\title{
LAS FORMAS DE CONSTRUCCIÓN EN ÁFRICA: UN MICROPROYECTO PARA TRABAJAR GLOBALMENTE LAS MATEMÁTICAS EN EDUCACIÓN INFANTIL
}

Sánchez Robles, María José; Fernández-Oliveras, Alicia; Oliveras Contreras, María Luisa. Universidad de Granada.

Fecha de recepción: 30 de junio de 2014.

Fecha de revisión: 5 de julio de 2014 .

Fecha de aceptación: 15 de julio de 2014.

\section{Resumen}

Este trabajo surge del actual concepto de "Etnomatemáticas", las matemáticas de las diferentes culturas, respondiendo por un lado a la cultura africana y, por otro, a la microcultura de un grupo de edad como es la de los niños de Educación Infantil. Tras un trabajo de investigación educativa, se diseño un "microproyecto" (un proyecto educativo que permite acceder a una pequeña parte de la cultura), eligiendo como tema a las casas africanas. A partir de este signo cultural africano, se expone una propuesta didáctica de educación intercultural, en la que se trabaja dicho signo desde distintos puntos de vista científicos con el fin de conseguir un aprendizaje globalizado. El trabajo se plantea desde un enfoque social-constructivista, buscando también un aprendizaje significativo. La implementación de este microproyecto en un aula real proporcionó datos que permitieron su evaluación.

Palabras clave: Constructivismo social, matemáticas, educación intercultural, aprendizaje basado en proyectos, estrategia globalizadora, formación de profesores.

La casa es un tema muy cercano al niño/a, ya que va a ser el lugar donde pasará gran parte de su tiempo, en los primeros años de su vida y, en consecuencia, donde se desarrollará y socializará.

A poco de nacer, las personas somos destinadas a un hogar, refugio donde crecemos junto a una familia, el principal agente socializador, quien cubre nuestras necesidades día tras día (INJUVE, 2012) la edad de abandono de la vivienda familiar en España, ronda los treinta años, causa de la crisis económica y las condiciones socioculturales del país).

Así, se hace patente la importancia de trabajar desde edades tempranas "La casa", un contenido presente en el área de "Conocimiento del entorno" (Real Decreto 2008, p. 123) y de fácil aplicación en Educación Infantil, aunque requiera de adaptaciones.

Hemos decidido ir más allá y tratar este tema a través de un microproyecto sobre "Las casas africanas" idea surgida tras llegar las prácticas y ver que en el centro había varios niños de África (Senegal, Etiopía...).

De este modo surge la combinación perfecta para realizar este trabajo, "la casa" como elemento esencial en la vida del ser humano y, por consiguiente cercano al mismo, y "africana" por la proximidad durante las prácticas a este continente que forma parte de algunas de las culturas presentes en el aula, a partir de las cuales se pueden trabajar las Etnomatemáticas. Los niños de estas culturas y sus familias nos facilitan la más 
rica de las informaciones sobre sus países de origen.

\section{FUNDAMENTOS TEÓRICOS}

La línea de investigación en la que se enmarca este trabajo, parte del innovador concepto de "Etnomatemáticas". D’Ambrosio (2007, citado en Giménez, Diez-Palomar \& Civil, 2007) lo explica así:

Para componer la palabra "etno-matema-tica" utilicé las raíces "tica", "matema" y "etno" para referirme a que hay varias maneras, técnicas, habilidades (ticas) de explicar, de entender, de tratar y de convivir con (matema) distintos contextos naturales y socioeconómicos de la realidad (etnos) (p. 97).

Oliveras (1996), define este concepto como:

Conjunto de todas las Matemáticas existentes, en tanto que consideramos a esta ciencia como un conjunto de prácticas específicas, realizadas por diversos tipos de personas y comunidades para el desempeño de cometidos diferentes que satisfacen sus intereses propios como grupo. Es decir, prácticas prototípicas que constituyen parte importante y representativa de culturas y microculturas diferentes $(p$. 115).

Por otro lado, Bishop (2000) afirma que "la Etnomatemática se refiere tanto al estudio de las relaciones entre las matemáticas y la cultura, como a las prácticas matemáticas concretas que se llevan a cabo dentro de las comunidades donde se halla ubicada la escuela" (p. 40). Finalmente, D'Ambrosio (2002) añade que la Etnomatemática es "la matemática practicada por grupos culturales, tales como comunidades urbanas y rurales, grupos de trabajadores, clases profesionales, niños de cierta fase etaria, sociedades indígenas y tantos otros grupos que se identifican por objetivos y tradiciones comunes a los grupos" (p. XI).

España es un país referente para los inmigrantes, por las buenas condiciones de vida de estos años atrás. Este fenómeno se ve reflejado en las aulas, donde gran parte de los alumnos son hijos de inmigrantes, o al menos uno de sus progenitores es extranjero. Dos ideas nos sugieren esto, la integración de dicho alumnado, y el aprovechamiento de las diferentes culturas para trabajar desde cada una de ellas (Vilella, 2007).

Sobre la integración hay mucho escrito, por ser un reto educativo de los últimos años. Pero se trata simplemente de integrar a las personas inmigrantes, sino de replantearse la escuela como espacio para la convivencia, teniendo en cuenta la diversidad. La escuela, junto a la familia, es un agente decisivo en la educación, y ésta, un pilar básico sobre el que se sustenta la convivencia (Observatorio de la Infancia en Andalucía [OIA], 2007). Es necesario, que desde la escuela se lleve a cabo una educación intercultural para TODAS las personas, no sólo para los inmigrantes, y que el fin sea convivir en armonía. Con ello obtendremos amplios beneficios, pues "El encuentro entre personas de culturas distintas es una oportunidad única para el enriquecimiento mutuo" (OIA, 2007).

En definitiva, una vez integradas las diferentes culturas en el aula, investiguemos sobre ellas y saquémosles todo el jugo posible, para trabajarlas según nuestras competencias. Pero, ¿cómo conseguirlo? Hay muchas formas de hacer las cosas, unos caminos llevan más lejos que otros, pero en todos aprendemos. En el proceso enseñanza-aprendizaje no iba a ser menos, existen diversas metodologías y en la variedad está el gusto. 
Kilpatrick (1919, citado por Godotti, 2008), estableció como características de un buen proyecto didáctico: "un plan de trabajo de preferencia manual, una actividad motivada por medio de intervención lógica, un trabajo manual teniendo en cuenta la diversidad globalizadora de enseñanza y un ambiente natural" (p. 150). Hernández y Ventura (1992) indican que la función de dicho Proyecto, "es posibilitar al alumnado el desarrollo de estrategias globalizadoras de organización de los conocimientos escolares mediante el tratamiento de la información" (p. 4). Podemos entender el Método por Proyectos, como una metodología en la que el proceso de enseñanzaaprendizaje es dinámico. Además, se parte del interés del niño/a, quien junto a sus compañeros/as, adquiere mayores responsabilidades para resolver una serie de situaciones problemáticas, logrando nuevos conocimientos.

Una variante del Método por Proyectos, son los "microproyectos", Oliveras (2005, p. 36) lo define como "Proyecto educativo, que permite acceder a una pequeña parte de la cultura con sentido en sí misma, que al ser estudiada desde distintos puntos de vista científicos provoque aprendizajes con significado global dentro del mundo infantil". Y añade las siguientes características:

- Metodología activa fundamentada en una perspectiva socio- constructivista.

- Objetivos que en la puesta en práctica creen significados contextualizados.

- Recursos seleccionados o creados en estrecha relación con los objetivos.

- Las actividades serán partes de un proceso mediante el cual se reconstruye la realidad, secuenciándolas de modo análogo a como se producen realmente.

El microproyecto parte de un signo que es algo más que un concepto: es un objeto o artefacto. Dicho signo forma parte de una cultura en la que adquiere gran relevancia, y además, tiene potencial de conocimientos, permitiendo que se trabaje desde las distintas áreas y a través de los diferentes lenguajes (matemático, plástico, musical...). Así, el microproyecto se convierte en una metodología óptima para trabajar en Educación Infantil.

\section{INVESTIGACIÓN ANTROPOLÓGICA}

La planificación de todo microproyecto, comienza con la investigación a fondo del tema a estudiar (Chávez, 2003). Previo a esto, hacemos una analogía entre la construcción de una casa y el desarrollo del pensamiento del niño/a, destacando que ambas requieren de unas bases sólidas, sobre las que ir desarrollando las siguientes fases del proceso, para culminar con un techo sólido que aúne todos nuestros logros.

\section{Estilos arquitectónicos}

La construcción de una casa, es un proceso muy importante en la vida del ser humano, pues implica la separación del nido familiar, para constituir uno nuevo. La casa es algo simbólico para la familia e imprescindible para su sentimiento de identidad (Brasey, 2013). En África, toda la familia se implica en la construcción de la vivienda, lo que requiere el esfuerzo de todos sus componentes, aunque en las tribus nómadas, el manejo y administración de la misma, recae sobre la mujer, ella la construye, es su dueña y su responsable, mientras los hombres desvían sus intereses hacía el pastoreo (Vélez, 2005).

La diversidad de pueblos que hay en África, impide hablar de un solo tipo de casa tradicional, más bien hay una amplia variedad de estilos arquitectónicos. A lo largo de su historia, diferentes grupos han ido ocupando el territorio africano, dejando su huella arquitectónica, lo que se refleja en la variedad de edificaciones (mezquitas, iglesias, 
pirámides, grandes ciudades, pequeños asentamientos nómadas) (Junta de Castilla y León). Bernard Rudofsky (1964), en su obra "Architecture Without Architects: A Short Introduction to Non-pedigreed Architecture", bautizó a la arquitectura espontánea como "arquitectura sin arquitectos". Ésta, es la que predomina en el continente africano y la que nosotros trabajaremos.

En el continente africano, se aprecian diferentes formas de construcción, en función del tipo de actividad (nómadas, seminómadas, sedentarios), materia prima disponible, clima, seguridad requerida y cualquier otra exigencia del entorno (Ortega, s. f.). Así, en las sabanas húmedas, construyen las paredes (circulares) con una estructura de palos y hojas cubiertas de barro, y el techo cónico con paja; en el bosque tropical se utilizan las fibras vegetales trenzadas, que obtienen de sus árboles; los nómadas utilizan materiales fácilmente desmontables y ligeros, como esteras y pieles, para su fácil transporte; y los Masáis de Kenia aprovechan el estiércol de sus preciadas vacas.

Pero existen características comunes que nos permiten hacer generalizaciones, como el frecuente empleo de "escalamiento fractal: pequeñas partes de la estructura tienden a parecer similares a las partes mayores como, por ejemplo, una aldea circular hecha de casas circulares" (Eglash Ron, 1999). Algunos tipos de estructuras son: en forma de colmena, cono en cilindro, cono en los polos, hastial techado, cono piramidal, rectángulo con techo redondeado y pendiente en los extremos, cuadrado, cúpula o techo plano en arcilla, cuadrangular en torno a un patio abierto, o cono en el suelo (Richard, 1976, p.71). La mayoría de estas estructuras, están formadas por un conjunto de edificios rodeados por una cerca; unos edificios están encerrados o conectados por murallas, otros entre dos vallas concéntricas (la de dentro para el ganado), otros alrededor de patios, etc. La disposición en círculos es la más común, y responde a una práctica defensiva (Junta de Castilla y León).

\section{Materiales}

Como antes mencionamos, la materia prima varía de unas zonas a otras del continente africano, así como la climatología, dos factores que influyen en el tipo de arquitectura propia de cada región.

Es común usar materiales naturales sin ningún tipo de derivado, aunque no siempre ocurra así. Por ejemplo, el cacao se utiliza en aquellas zonas donde abunda, como protector de las viviendas, impermeabilizándolas (como pasta) o ahuyentando a los insectos (como líquido residual) (Vélez, 2005). Destacamos el barro (en ocasiones con agregados menores), pues como indica Vélez, su plasticidad, sensibilidad ecológica, y bajo coste económico, lo elevan en el ranking de materiales preferentes en África. Pero además, es un material muy duradero. Añade este autor, que las tribus que creen que los espíritus de los familiares pueblan sus casas, se niegan a demolerlas, y llegan a perdurar hasta más de trescientos años.

En la arquitectura africana, también está muy presente el adobe, una "masa de barro mezclado a veces con paja, moldeada en forma de ladrillo y secada al aire, que se emplea en la construcción de paredes o muros" (Real Academia Española, 2009). La mezcla con paja, le aporta mayor fuerza al barro; aún así, se utilizan materiales más sólidos en la base y como revestimiento para evitar la humedad. (Vélez, 2005).

\section{Tipos de casas:}

Tiendas nómadas: Las tiendas nómadas, se construyen a partir de una estructura curva de cañas entramadas (Figura 1, izquierda) sobre la que se ponen pieles de 
cabra o esterillas de palma, solapadas (Figura 1, derecha). Los nómadas emplean materiales fáciles de desmontar, ligeros $y$, por consiguiente, de fácil traslado en sus viajes.

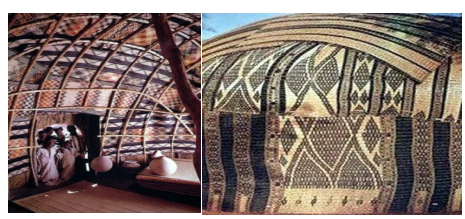

Figura 1: Tiendas nómadas africanas construidas con esterillas de palma. Fuente: http://www.vitruvius.com.br/revistas/read/arquitextos/05.057/496

Una admirable artesanía es la de los pueblos pastores semi-nómadas de Suráfrica; estos confeccionan sus casas con esterillas de junco, que disponen sobre la estructura de cañas entramadas, que la sostiene (Figura 2, izquierda); También son utilizados los juncos en Senegal (Figura 2, derecha) que, como dice el arquitecto Vélez, dejan ver una "obra ordenada, elegante, pura, limpia, de amorosa artesanía, aprovechando al máximo la materia prima disponible. Y, lo que resulta más difícil de apreciar a primera vista: la fuerza expresiva de esta arquitectura anónima que surge de un esfuerzo colectivo espontáneo y armonioso".

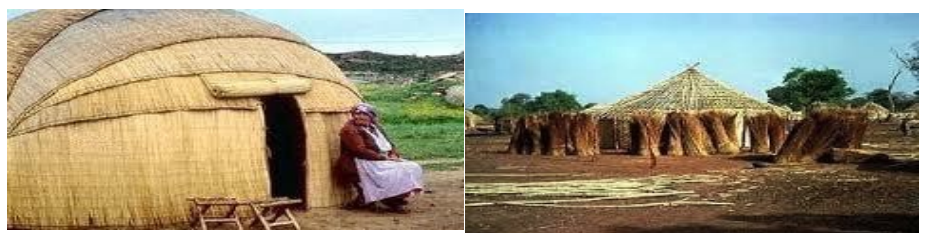

Figura 2: Tiendas nómadas africanas construidas empleando juncos. Fuente: http://www.vitruvius.com.br/revistas/read/arquitextos/05.057/496

Arquitectura de arcilla Decorada: Este tipo de casas son una muestra de la cultura de los Gurunsi. Se asemejan a grandes vasijas semienterradas en la arena, decoradas con tintes naturales tanto en su interior como en su exterior (Figura 3, izquierda). Este es uno de los casos en que las mujeres son las responsables absolutas de la elaboración de la vivienda. La protección climática que efectúan, viene de la mano del robustecimiento de los frisos.

Arquitectura de barro: Según Vélez, el origen de la arquitectura del barro puede situarse Mali y presenta una gran variedad de formas (Figura 3, derecha). En Djenné, destaca la Gran Mezquita, la construcción en barro más grande del mundo. En Timbuctú trabajan con una mezcla de mortero de barro y yeso, al que añaden piedra picada, consiguiendo un material compacto y resistente. Esta característica diferencia la arquitectura de esta ciudad. En cuanto a decoración de techos y fachadas, recuerda a la práctica de las ciudades bereberes de piedra.

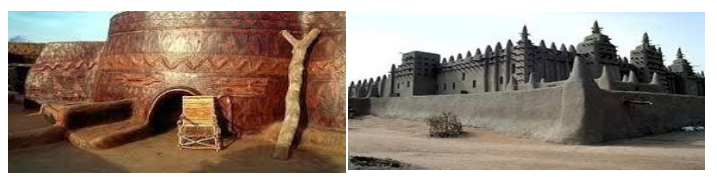

Figura 3: Ejemplos de arquitectura de arcilla decorada (izquierda) y barro (derecha). Fuente: http://apuntesdearquitecturadigital.blogspot.com.es/2010/09/barrio-viento-y-sol-raices-de-una.html

Viviendas Dogon: Son viviendas y graneros de barro construidas sobre la roca (Figura 
4). La "Tierra Dogon" era un lugar estratégico defensivo. Construyeron allí sus casas, porque era una zona escarpada, a la que era difícil acceder, y así se protegían de sus enemigos.

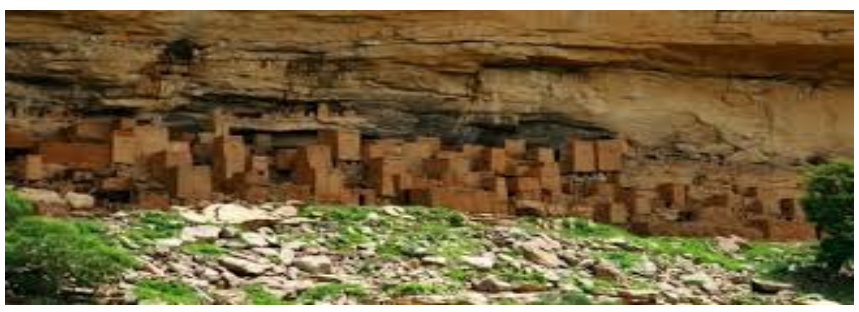

Figura 4: Ejemplo de viviendas Dogon en Mali. Fuente: http://www.nedobandam.com/el-pais-dogonla-autenticidad-en-el-corazon-de-africa.html

Arquitectura capsular. Este tipo de arquitectura, típico de Camerún, se caracteriza por paredes de barro muy delgadas (de unos tres centímetros) y surcos que resaltan (Figura 5, izquierda). La idea de estos surcos, es evitar el desgaste que la lluvia produce, al canalizar el agua en distintas direcciones. Además, permiten el ascenso a la cúpula, necesario para el mantenimiento antes del periodo de lluvia. Para diferenciar las casas de las diferentes familias, se hacen distintos patrones en esos surcos. Las casas con techos tejidos de palma, son otro tipo de arquitectura capsular (Figura 5, derecha).

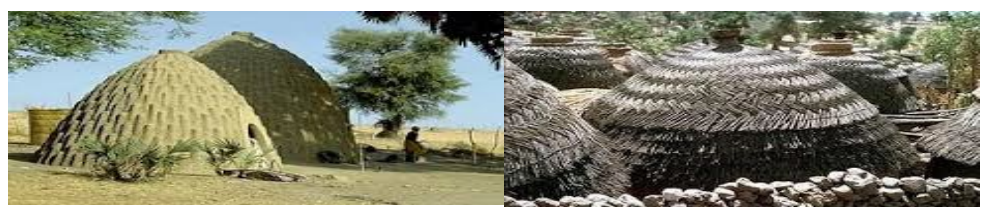

Figura 5: Ejemplos de arquitectura capsular de Camerún. Fuente: http://www.vitruvius.com.br/revistas/read/arquitextos/05.057/496

Casas 'a impluvium' de Casamance: Son casas circulares con un patio interior, que tiene un depósito de agua central. El tejado tiene forma de embudo y cuando llueve, vierte el agua de lluvia en el depósito Alrededor del patio están las habitaciones, con pequeñas ventanas. Sólo hay una puerta, que cerraban herméticamente para defenderse de sus enemigos (Martínez \& Strubell, 2013).

Casas de barro: Están hechas de barro y heces de vaca o paja, materiales abundantes en las zonas en que se construyen, y no tienen ningún coste económico. Además, el barro mantiene el interior fresco (Figura 6, izquierda).

Casas de paja: Es una arquitectura similar a la de los nómadas; tiene una estructura de cañas entrelazadas, y sobre ellas, paja o cualquier otro tipo de vegetación, seca (Figura 6, derecha). La paja es un material impermeable muy resistente, que además de dejar pasar el aire, impide la entrada del agua. Otro tipo de casa de paja es la típica de Kenia. Es una casa circular con techo de paja, que se sujeta por capas a la estructura, que es de madera.

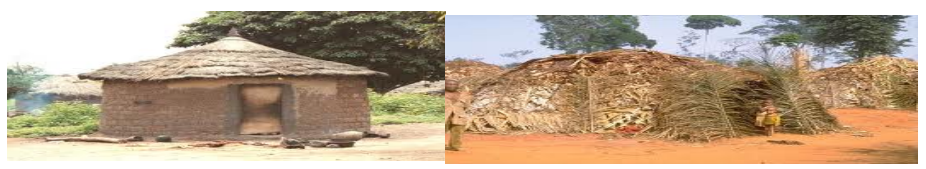

Figura 6: Ejemplos de casas de barro y paja. Fuente: http://nanito.wikispaces.com/Casas.De.Africa 


\section{Decoración:}

La arquitectura africana, es fuente de inspiración para los arquitectos, por su expresión creativa y auténtica. Diseñadores como Gaudí, Corbusier, Barragán, y Gehry, entre muchos otros, han expresado en sus obras la importancia e influencia que ésta ha tenido en la evolución de la arquitectura.

Las casas de Tiébélé (Figura 7) son un ejemplo representativo de decoración africana. Los hombres construyen la casa con adobe y las mujeres decoran su exterior. Primero dan una capa de barro con estiércol de vaca, al que añaden agua para poder extenderlo bien con la mano. Antes de que se seque, marcan las líneas de los patrones a seguir, y preparan el pigmento con arena roja, excremento de vaca más oscuro, o polvo de roca. Dejan secar la base inicial y la repasan con canto rodado para que quede pulido. Una vez seco, dibujan con el pigmento (ayudándose de las manos o pinceles de pluma de gallina) los motivos geométricos u otros como calabazas, alas de halcón, murciélagos, boas, tortugas, cruces, la pipa y el lagarto. Al secarse, pulen la superficie con ramas para garantizar su calidad. Los motivos, dependen del estatus social de la familia. Las casas rectangulares, son para los recién casados, las redondas para los jóvenes y las de forma de ocho para abuelos y nietos (Alexa, 2012).

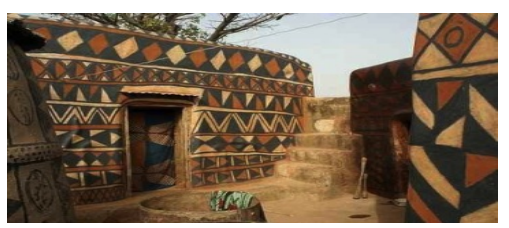

Figura 7: Ejemplos de casas Tiébélé. Fuente: http://www.futuropasado.com/?p=2881

\section{Nueva arquitectura}

Una nueva arquitectura ha surgido en África, en estos últimos años. Dos problemas fueron los desencadenantes: la escasez de viviendas y la gran cantidad de botellas de plástico que se encuentran por las calles. La Asociación de Desarrollo de Energías Renovables (DARE), comenzó en junio de 2011 un proyecto basado en la construcción de casas, utilizando botellas de plástico en su estructura. Las botellas se llenan de arena, se unen entre sí por el cuello con una red en cadena, se colocan estratégicamente y se compactan con barro y cemento. Los fondos de las botellas son de colores, aportando un toque de diseño (Figura 8). Estas casas son muy resistentes y mantienen una adecuada temperatura interior. Es un método sencillo, accesible y barato, que además de limpiar las ciudades, hace un aporte a la escasez de vivienda (Sanz, 2012; Franco 2011).

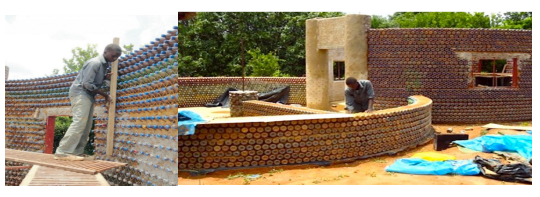

Figura 8: Ejemplos de casas fabricadas con botellas de plástico recicladas. Fuente: http://ecologismos.com/casas-con-botellas-de-plastico-en-africa/casas-con-botellas-de-plastico-en-africa3/

\section{MICROPROYECTO}

Para llevar a cabo el microproyecto debemos aclarar el concepto de "casa", comprender la importancia del hogar, conocer los tipos de casas existentes, y 
sumergirnos en el proceso de construcción de las mismas. Con ello desarrollamos las capacidades del niño en el ámbito emocional, cultural, motriz, cognitivo... siguiendo la secuencia lógica de aprendizaje de: acción, reflexión y representación.

Este microproyecto va dirigido al segundo ciclo de Educación Infantil, por requerir conceptos previos y habilidades manipulativas, no adquiridos en etapas anteriores. Así mismo, elijimos los cursos de 4 y 5 años, porque a la hora de crear las actividades, es necesario que se haya adquirido un mínimo de lectoescritura, mayores habilidades manuales y desarrollo madurativo. Su aplicación es posible en cualquier contexto, (urbano-rural), pues todos los niños escolarizados tienen una residencia o contacto con algún tipo de de casa. Trabajar la multiculturalidad, con los tipos de casas, nos permite llevar el proyecto a cualquier escuela del mundo, realizando pequeñas adaptaciones en las actividades.

La metodología del microproyecto es global, por desarrollar habilidades y conocimientos de las áreas del currículum de infantil, sin segregación alguna, así como activa y participativa, pues el niño/a es el protagonista. Además el microproyecto se basa en el juego, siendo su metodología lúdica, ya que se divierten aprendiendo. Por último, es diversificadora, ya que atendemos a las necesidades individuales de cada alumno/a, empleando diversos formatos en las actividades (audio, imagen, material manipulativo) y adecuando su complejidad, a las características del niño.

El maestro/a será orientador/a y guía, presentando los temas e induciendo a los niños/as a la reflexión y el diálogo, mostrándose comprensiva y flexible, en la temporalización y desarrollo de las actividades. Los motivará en todo momento, para lograr su interés y conseguir un aprendizaje adecuado y efectivo.El niño/a, estará implicado de forma individual y colectiva, en su proceso de aprendizaje, explorando, investigando y manipulando materiales, con una actitud positiva hacia la actividad. Su opinión y sentimientos se tendrán en cuenta en cada momento.

Nuestro microproyecto se divide en ocho sesiones, para desarrollar en 15 días variables, en función del ritmo de la clase. Las actividades se plantean de modo progresivo, teniendo en cuenta la actitud del alumnado y siendo flexibles al desarrollarlas, pues el fin es aprender y no trabajar a contrarreloj.

\section{IMPLEMENTACIÓN}

\section{Objetivos}

El objetivo general del microproyecto es:

- Tomar conciencia del uso e importancia de la casa, conociendo sus procesos de construcción y los diferentes tipos existentes, en el contexto africano.

Los objetivos específicos de las actividades, presentados en el orden en que éstas se realizan, son:

- Reconocer las letras que forman las palabras.

- Clasificar mediante criterios dados.

- Reconocer posibles errores y argumentarlos.

- Cumplir las características de la fase del dibujo propia de su edad.

- Comprender lecturas y expresar con claridad las ideas.

- Atender en situaciones de escucha pasiva. 
- Formular hipótesis y comprobarlas.

- Medir cantidades.

- Desarrollar el pensamiento lógico.

- Demostrar actitudes de respeto a las diferencias culturales.

- Conocer diferentes formas geométricas y reconocerlas en elementos del entorno.

- Hacer construcciones tridimensionales, a partir de un dibujo en el plano.

- Discriminar atributos.

- Manejas los conceptos alto-bajo, grande-pequeño, ancho-estrecho, arriba-abajo, dentro-fuera, duro-blando.

- Corresponder una cantidad con su número.

- Conocer las mayúsculas y minúsculas y escribirlas con claridad.

- Hacer seriaciones con figuras geométricas.

- Desarrollar la ordenación de las fases de una secuencia.

- Representar la realidad mediante un dibujo.

- Construir un elemento a partir de unos materiales, siguiendo las fases de un proceso.

\section{Contenidos}

Los contenidos que se trabajan, son:

- La clasificación, seriación y ordenación.

- La casa: concepto, importancia, materiales, construcción, tipos.

- Las figuras geométricas.

- Las letras: mayúsculas y minúsculas.

- Medida de cantidades.

- El método científico.

- El arquitecto.

\section{Actividades}

Comenzamos con una asamblea, donde recogemos los conocimientos previos del alumno sobre el concepto de "casa", su construcción, y los tipos existentes. Mediante una lluvia de ideas, permitimos al niño expresar cuanto quiera sobre el tema planteado. Posteriormente realizamos unas preguntas para guiarles en el debate, tales como: ¿qué es una casa?, ¿qué tipos hay?, ¿cómo se construyen?, ¿son todas iguales?, ¿cómo es vuestra casa?, ¿son importantes?, ¿por qué?, ¿para qué sirven?

\section{$1^{\text {a }}$ Sesión:}

Objetivo: comprender el concepto de casa diferenciándola de otros elementos. Colocamos en la pared un franelógrafo divido es dos partes, una bajo el rótulo "Casa" y otra de "No casa".

El maestro/a reparte una letra a cada niño/a (bocabajo), las que forman esos rótulos, y otras de relleno, (tantas como alumnos). Entre todos, dicen las letras que componen estas palabras, y la maestra las escribe en la pizarra. Después, se inicia un minijuego en que con rapidez, los niños levantan sus letras, identifican si están en las palabras de la pizarra, y en ese caso, salen a ella con su letra en alto, colocándose ordenados para formar las palabras. El maestro/a y el resto de niños corrigen cualquier fallo en el orden de las letras. Luego, cada niño coloca su letra en el encabezado del franelógrafo, y regresa a su sitio. Mientras, el maestro/a reparte a los niños/as que no han salido, una serie de imágenes. A la señal del docente, los niños/as levantan sus 
imágenes y con rapidez, las clasifican en "casas", o "no casas". El resto de compañeros, corrigen posibles fallos, siempre argumentando el por qué. La maestra media y les incita a la reflexión mediante preguntas como: ¿por qué no es una casa o por qué sí?, ¿puede vivir la gente dentro o no?, asegurando que comprenden el concepto. Finalmente, cada niño elige la imagen de "casa" y "no casa" que más le gusta y la dibuja en cartulina escribiendo el rótulo correcto.

\section{$2^{a}$ Sesión:}

Objetivo: comprender la importancia de tener una casa.

Comenzamos la actividad contando una historia para que el alumnado tome conciencia de la importancia de la casa. Algunos de los padres pueden narrar el cuento o representarlo con un teatro, con marionetas, etc. Contado el cuento, hacemos preguntas de comprensión de la lectura, que responden oralmente los niños/as, para verificar que lo han entendido. Posteriormente se abre una sesión de diálogo con la pregunta ¿Qué os parece la historia?, donde los niños/as exponen sus ideas; y continuamos preguntando "¿por qué es importante una casa?", haciéndoles reflexionar sobre el tema. Seguidamente hacemos un experimento siguiendo una metodología inspirada en el Método Científico, que culmina con la decoración del producto final.

\section{3ª Sesión:}

Objetivo: tomar conciencia de las formas geométricas en el entorno, no percibiéndolas como algo aislado.

Iniciamos mostrando a los niños/as imágenes, de las diferentes casas de África (recogidas en el apartado de investigación antropológica), las comentamos juntos y preguntamos ¿Qué forma tienen?, ¿Como un cuadrado, como un triángulo?, y lo discutimos. A continuación repartimos a cada niño/a plantillas (Figura 9) sobre las que deben colocar los bloques lógicos, y ver las figuras geométricas que las componen. Seguidamente, proyectamos imágenes de paisajes y objetos cotidianos, para identificar las figuras geométricas presentes en ellos. Después, damos una ficha con las diferentes formas geométricas, dentro de las cuales dibujarán cosas del entorno, con la forma de las mismas, y escribirán sus nombres. Por último, proporcionamos al alumnado material estructurado de pinchos que se enganchan entre sí, bloques de construcción, Legos y tela, para que construyan las casas.

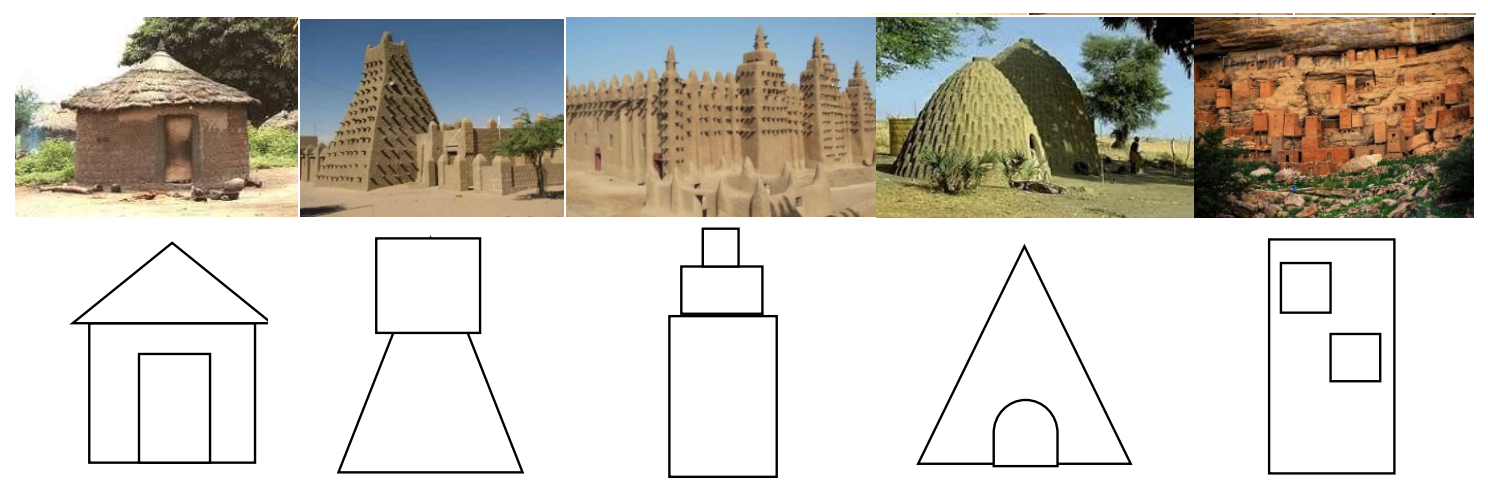

Figura 9: Imágenes de diferentes casas africanas y plantillas para su construcción con bloques lógicos. 


\section{4ª Sesión:}

Objetivo: conocer el concepto de arquitecto e identificar el primer paso para llevar a cabo la construcción de una casa.

Comenzamos con una asamblea preguntando ¿cómo son nuestras casas?", para iniciar un debate sobre sus características. Seguidamente cuestionamos ¿cualquiera puede hacer una casa?, ¿quién las hace, una persona o varias?, ¿cómo se ponen de acuerdo? Mediante el diálogo conoceremos, que antes de hacer una casa hay que saber cuál va a ser su forma, sobre qué terreno se construirá, su tamaño, sus materiales, etc. induciendo con ello a la figura del "arquitecto". Nos convertimos en arquitectos por un día. Dividimos la clase en pequeños grupos, donde unos serán arquitectos, y otros obreros. Los arquitectos dibujan en un papel, una casa, e indican el lugar de la clase donde construirla. Los obreros, mirando el dibujo, construyen la casa con cajas de cartón de diferentes tamaños, telas, rotuladores, etc., identificando bien las formas, y componentes de la misma (ventanas, puertas), comparando y reflexionando. Finalizamos con una asamblea, donde hablamos de la situación del arquitecto en África, trasmitiendo la información recogida sobre los condicionantes de la arquitectura africana (clima, materiales que abundan, actividad). Un dibujo de lo aprendido en el día concluirá la sesión.

\section{5ª Sesión:}

Objetivo: comprender la importancia de los materiales en la construcción de una casa.

Vemos la película de "Los tres cerditos" en la cual aparecen casas construidas con diferentes materiales. Tras verla, centramos el diálogo en dichos materiales, reflexionando sobre la resistencia y propiedades de los mismos, y apreciando la importancia de su elección. A continuación, mostraremos las casas de África utilizadas en otras actividades, y entre todos veremos los materiales con los que están hechas. Seguidamente, damos a cada niño/a dos fichas, una con diferentes imágenes de estas casas, (para recortar), y la otra con los rótulos "1 PIEDRA, 5 BARRO, 2 PALOS, 1 TELA, 2 HIERBA SECA". Cada rótulo, han de escribirlo de nuevo, pero en minúsculas, y recortar y pegar al lado de cada uno de ellos, tantas imágenes de casas como número nos indican, (respondiendo al material que nos dice). Por ejemplo, bajo "5 BARRO", escriben " 5 barro", y a su lado se pegan cinco casas que se hagan con barro. Finalmente representamos el cuento de los tres cerditos. Podemos comenzar representando la versión original, y después versionarla para hacerla más divertida.

\section{6ª Sesión:}

Objetivo: hacer seriaciones con figuras geométricas.

Comenzamos con el visionado de "Mujeres Tiébélé poblado pintado con figuras geométricas y patrones geométricos". Seguidamente, comentamos en grupo el video, haciendo una ronda de preguntas y exposición de ideas. Destacamos las figuras geométricas, la seriación, y la mezcla de pigmentos. Procedemos a decorar nuestra casa Tiébélé. Tomamos una caja de zapatos, que pintamos en tonos rojizos con pintura y rodillo. A continuación hacemos las seriaciones con figuras geométricas, bien pegando gomets, bien dibujando las formas a lápiz, y pintándolas con rotulador o pintura. Cada niño elegirá sus figuras, pero siempre, haciendo una seriación. Finalmente, se decora con líneas, objetos o animales, como los de la tribu Tiébélé, y se le ponen las puertas y ventanas, haciéndolas en un folio y pegándolas después en la caja. Podemos ampliar la actividad, incluyendo una tarea en el que los niños/as 
hagan mezclas de colores con lápices, ceras, rotuladores y pintura y, a modo de experimento científico, planteen hipótesis y las comprueben. Sus conclusiones pueden representarse tal como: rojo + amarillo $=$ naranja, coloreando círculos adecuadamente además de escribir los colores.

\section{$7^{a}$ Sesión:}

Objetivo: ordenar las fases de una secuencia.

Vemos el video "Construcción de casa de barro en Comunidad-África" y lo comentamos, haciendo preguntas, y aportando ideas relacionadas con el mismo. Visto el video, cada niño/a dice una acción de las que en él aparecen y el/la docente las anota. Recogidas todas las acciones importantes se reparten entre los niños/as, quienes deben dibujarlas en un folio. Una vez acabados los dibujos, ordenamos nuestra historia. Con el maestro/a como guía, hacemos una fila de niños/as (cada uno con su dibujo visible) en la que se aprecia la secuencia correcta. "¿Qué hacen primero?- Van las mujeres a por agua- ¿Quién lo ha dibujado?" (y así sucesivamente). Ante opiniones contrarias se dialogará hasta llegar a un acuerdo. Finalmente, volvemos a ver el video, comprobamos si hemos ordenado bien nuestra historia, y ante algún fallo, detenemos el video, y los niños se autocorregirán. Acabado el ejercicio, encuadernamos los dibujos, para crear un nuevo libro para la biblioteca.

Nota: el/la docente irá traduciendo el video y ayudará a sacar las acciones, para que no quede ninguna importante sin decir.

\section{$8^{a}$ Sesión:}

Ya sabemos cómo se hace una casa, ahora construyamos una a nuestra medida. Mostramos a los niños/as botellas de plástico de dos litros, fixo ancho, una sombrilla de playa, papeles de diferentes colores y texturas (celofán, charol), pinceles y pintura, y lanzamos al vuelo la pregunta "¿cómo podemos construir una casa con todo este material?". Los niños/as hacen sus cábalas, y tras dialogar, les mostramos las imágenes de las casas africanas hechas con botellas de plástico, explicándole su historia. En una cartulina, dibujamos las fases del proceso, para que los niños visualicen el trabajo a realizar (pasada una fase, se tacha aquí).

Las fases serían:

1. Construcción de la estructura: el trabajo recae más sobre el adulto, quien debe unir las botellas para hacer la estructura (contamos con los padres), pero los niños no están parados, alargan las botellas a los adultos, quienes las colocan formando un círculo, y fijándolas con fixo. Las dimensiones serán acorde con la altura de los niños, además tendrá una puerta y alguna ventana. (Variará dependiendo de la habilidad y creatividad de los adultos).

2. Decoración: la mitad de la clase pintará con diferentes colores (pintura y pincel), los salientes del culo de las botellas, pero sólo, de la mitad inferior de la casa. En el interior verán los colorines de los tapones, y por fuera, los culos multicolores. La otra mitad de la clase hará la parte superior, dibujando en papel continuo la decoración propia de la tribu Tiébélé (seriaciones y adornos), con pintura y pincel. A mitad de trabajo, cambiarán se cambiarán las tareas.

3. Hacemos el tejado: repartimos papeles de diferentes tipos a los niños, para que las recorten haciendo tiras. Seguidamente, se colocarán con cola sobre la sombrilla de 
playa abierta (elegida por su forma cónica, pero caben otras opciones), y simular así la paja de los tejados africanos.

4. Últimos detalles: una vez seco, colocamos el papel continuo Tiébélé en la mitad superior de la casa, y el tejado sobre la estructura, finalizando nuestra casa Africana. La colocamos en el mejor sitio de la clase, y disfrutamos de ella, jugando, y respetándola.

Nota: requiere ayuda de adultos. Las canciones que las mujeres africanas cantan en el video, se pondrá de fondo mientras trabajamos.

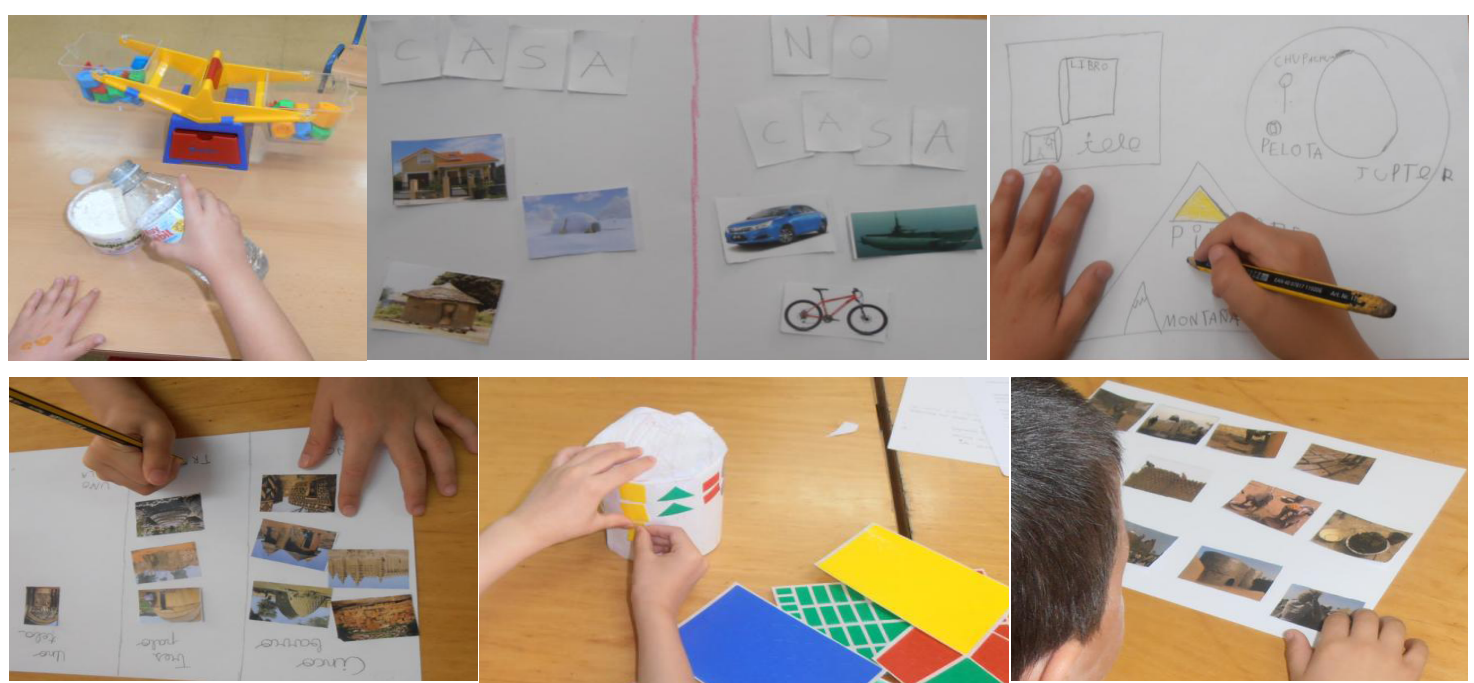

Figura 10: Imágenes de la implementación de las actividades propuestas en el microproyecto. De izquierda a derecha y de arriba a abajo: $1^{\mathrm{a}}, 2^{\mathrm{a}}, 3^{\mathrm{a}}, 5^{\mathrm{a}}, 6^{\mathrm{a}}$ y $7^{\mathrm{a}}$ sesiones.

\section{Evaluación}

Este microproyecto se evalúa mediante la observación, directa y continúa del proceso de aprendizaje de nuestros alumnos, teniendo en cuenta el nivel de logro de los objetivos en cada actividad.

Tras la implementación podemos decir que este microproyecto es efectivo para el trabajarlo en el aula de Educación Infantil, pues responde a las exigencias marcadas por ley en cuanto a contenidos, metodología, y adaptación. Así mismo, el tema de dicho microproyecto proporciona multitud de ideas para la elaboración de actividades.

\section{CONCLUSIONES}

- Todas las culturas piensan matemáticamente, y en ese sentido las matemáticas son universales, pero cada cultura tiene sus peculiaridades, y debemos atender a su diversidad.

- La identificación de las matemáticas con aspectos de la vida o cosas cotidianas, hace que se pierda el tabú sobre ellas y en la Educación Infantil debe darse su inicio.

- Cómo metodología para el proceso de enseñanza-aprendizaje destaca, por sus condiciones, el microproyecto. Globaliza, no es excesivamente extenso, y no parte de un contenido, sino de un signo cultural, que al estudiarlo permite al niño desarrollar todas las áreas del currículum, incluyendo las matemáticas. 
- Los conocimientos significativos obtenidos, tras su aplicación en el aula, demuestran la efectividad del mismo.

\section{BIBLIOGRAFÍA}

Alexa (2012). Casas de adobe decoradas. El Baúl Manualidades. Montevideo, Uruguay. Octubre 27.

Rudofsky B. (1964). Architecture without Architects: a Short Introduction to Nonpedigreed Architecture.

Bishop,A. (2000). Matemáticas y educación: retos y cambios desde una perspectiva internacional. Barcelona: Graó.

Brasey, D. (2013). La importancia del hogar para los niños. Pnlnet.com

Chávez. A. (2003). El método de proyectos: una opción metodológica de enseñanza en primer grado de Ed. Primaria. Tesis para obtener el grado de Maestra en Educación en el campo de la intervención pedagógica aprendizaje escolar. Universidad Pedagógica Nacional.

D’Ambrosio, U. (2002). Etnomatemática. Eslabón entre las tradiciones y la modernidad. Belo Horizonte: Autêntica.

Giménez, J. Diez-Palomar J. y Civil M. (Eds.), (2007), Educación Matemática y Exclusión (Pág 97). Barcelona, España: Graó.

Eglash, R. (1999). African Fractals: Modern computing and indigenous design. Rutgers.

Franco, J.T. (2011). La primera casa de botellas d África. Plataforma Arquitectura.

Godotti, M. (2008). Historia de las ideas pedagógicas. México: Siglo XXI.

Hernández, F. y Ventura, M. (1992). La organización del currículum por proyectos de trabajo. En Piquín, R. (2005). Proyectos documentales integrados: una experiencia tecnológica entre bibliotecas y escuelas. Travesía.

INJUVE (2012). Jóvenes y emancipación en España. Gobierno de España, Ministerio de Sanidad, Servicios Sociales e igualdad. Octubre 29.

Junta de Castilla y León. Las viviendas tradicionales africanas. Artehistoria.jcyl.es

ORDEN ECI/3960/2007, de 19 de diciembre, por la que se establece el currículo y se regula la ordenación de la educación infantil. Real Decreto, 2008.

Martínez, I., Strubell, P. (2013). Viajamos a Senegal: Las sorprendentes casas de la Casamance. (Casa África). Blog.africavive.es

Observatorio de la Infancia en Andalucía [OIA] (2007). Educación infantil e interculturalidad. (pp. 15-54) Granada: Consejería para la Igualdad y Bienestar Social. 
Oliveras, M.L. (1996), Etnomatemáticas. Formación de profesores e innovación curricular. Granada: Comares.

Oliveras, M. L. (2005). Microproyectos para la educación intercultural en Europa. Uno: revista de Didáctica de las Matemáticas, 11(38), 70-81.

Ortega. J.F. (s. f.) África subsahariana. Africaclub.com (Segovia-España).

Real Academia Española (2009). rae.es

Richard W. H. (1976). African Cities and Towns before the European Conquest (Pág. 71). Nueva York: W. W. Norton \& Company.

Sanz, D. (2012). Casas con botellas de plástico en África. Ecologismos.

Vélez, G. (2005). Barro, viento y sol. Raíces de una arquitectura africana. Vitruvius, Arquitextos. apuntesdearquitecturadigital.blogspot.com.es/2010/09/barrioviento-y-sol-raices-de-una.html

Vilella, X. (2007). Matemáticas para todos, Enseñar en un aula multicultural. México: Lukombanda, Editorial SA DF CV.

Wikipedia.org. Arquitectura africana. 